\title{
UK tightens regime for animal research
}

[LONDON] The UK government has agreed to strengthen the law on the use of animals in research. The number of inspectors will be increased, and scientists applying for a licence for an animal experiment will have to explain why a non-animal alternative is unsuitable.

But, despite a pre-election pledge by the Labour government to restore a previous cut, there is little new money to fund research into non-animal alternatives. Nor is there a promise to ban the use of animals in cosmetics testing, another pledge.

The decisions were announced last week by Jack Straw, the Home Secretary, in response to the publication of an interim review of the 1986 Animals (Scientific Procedures) Act by a committee of government advisers.

Animal rights lobby groups, as well as those representing scientific research, have broadly welcomed the review. But both sides have criticized the decision not to restore funding for research into non-animal alternatives to its level of two years ago. The sum was reduced to $£ 182,000$ last year by the then Conservative government. Labour has agreed to increase the amount by $£ 20,000$, still less than the $£ 250,000$ spent in 1995.
Les Ward, director of Advocates for Animals and a member of the Home Office advisory committee that reviewed the legislation, describes the extra funding as a "pittance", and Robert Coombes, scientific director of the Fund for the Replacement of Animals in Medical Research, says it is "abysmal"."Each major project needs around

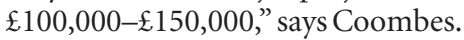

Mark Matfield, director of the Research Defence Society, agrees that the government should spend more on investigating alternatives. He says that although most of the funding for alternatives comes from industry, the level of government support indicates "how much importance it attaches to alternatives".

The review recommends increasing the "public understanding of the principles behind cost-benefit assessments, the method by which the suffering of animals is weighed against public benefit". The sentiments behind the recommendation have been welcomed, although observers remain unclear about what it means in practice, and some remain sceptical about what it will achieve.

Maggy Jennings, director of the animals in research division of the Royal Society for the Prevention of Cruelty to Animals, says the general public does not approach this issue in terms of costs and benefits.

Laurence Smaje, director of the medicine, society and history division of the Wellcome Trust, says that surveys show "most people think that experiments are done on cats and dogs to test cosmetics".

He says an explanation of the methodology of cost-benefit assessments will help individuals already engaged in the debate about the use of animals in experiments, but will be meaningless to others.

Smaje says that public understanding of the debate about animals in research requires broader initiatives aimed at different audiences, particularly schools and universities, but also involving museums and science centres. He says that this last group has been reluctant to give space to the issue of animals in research, from fear of being targeted by animal rights extremists.

Another challenge, Smaje says, is to persuade teachers who oppose the use of animals in research to encourage a balanced debate in classroom discussions. He also believes the question of animals in research should be discussed during undergraduate science courses at universities. Ehsan Masood

\section{Astronomers review options after fire ravages gamma array}

[MUNICH] Astronomers are assessing the damage caused by a fire that raged last week through the site of the High-Energy Gamma Ray Array (HEGRA) at La Palma in the Canary Islands (pictured right), only months before it was due to start operating at full capacity.

The array, a collaborative project run by laboratories in Germany, Spain and Armenia, detects and analyses cosmic rays and gamma rays hitting the Earth, and searches for galactic and extragalactic gamma-ray sources.

The fire appears to have been connected with the burning of scrub during landscaping activities in the national park in which HEGRA is situated. National park regulations stipulate that the site may not be cleared of scrub, and the tinder-dry gorse bushes burning between the detectors caused most of the damage.

HEGRA comprises a 200-square-metre chequerboard system of gamma-ray detectors, known as Cherenkov counters. These are punctuated by six imaging Cherenkov telescopes which are the most sensitive ground-based gamma-ray detectors in the world.

One-third of the array detectors and one of the telescopes were destroyed by the fire, at a cost estimated at between DM1.3 million and DM1.6 million (US\$730,000$\$ 900,000)$. Further damage to the

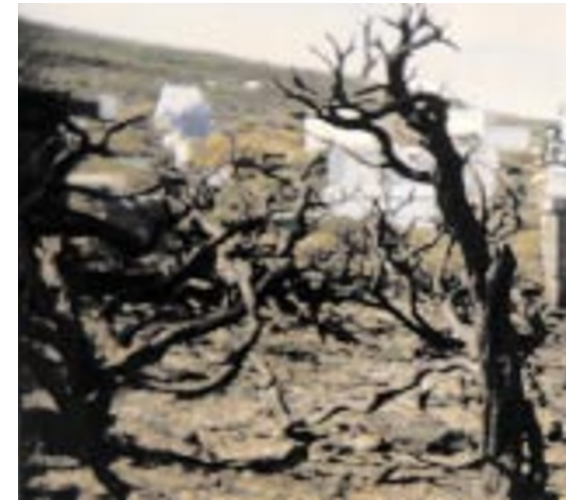

instruments' sensitive electronics by hydrochloride vapours released from burning plastic may be revealed later, according to Heinrich Völk, a director at the Max Planck Institute for Nuclear Research in Heidelberg, and a spokesman for the project.

Völk says the observatory was saved from complete destruction by scientists based at the site, who tried to bring the fire under control with extinguishers before the fire brigade arrived, as well as by a fortuitous change in wind direction.

In its various stages of completion, HEGRA had been operating for about six years. Four telescopes had been operating since the end of last year. Completion of the entire stereoscopic system of six telescopes was expected this winter.
HEGRA scientists are still able to work with the undamaged detectors and telescopes, but at greatly reduced sensitivity and efficiency. They are discussing possible compensation with insurance agencies. But because of laws restricting insurance cover of equipment bought with public money, the instruments' total value is not covered.

Also, as Völk points out, money is not the only problem when replacing damaged instruments. "They are not off the shelf," he points out. Laboratory staff who built them are not necessarily available to rebuild them.

The HEGRA teams will be asking for help from the agencies that have paid most of the costs of the multimillion dollar project - the German federal research ministry and the Max Planck Society.

A lis on A bbott 